\title{
LONG TERM CHANGES IN FLOODING AROUND GIFU CITY
}

\author{
K. Toshiharu ${ }^{1}$, Ch.Narantsetseg ${ }^{2}$ \\ ${ }^{1}$ River basin research center, Gifu University, Gifu 501-1193, Japan; E-mail: kojima@green.gifu-u.ac.jp \\ ${ }^{2}$ Graduate School of Engineering, Gifu University, Gifu 501-1193, Japan; E-mail: nrntstsg@gmail.com
}

KEY WORDS: 2D Flood inundation simulation, long term changes in flood risk, levee effect

\begin{abstract}
Heavy rainfall within a short period and consequent high river discharge are results in floods which subsequently creates huge infrastructure problems for areas, such huge economic deficits in production as well as damages to existing property and goods, even loss of human lives. In about hundred years ago the flat-land around the Kiso Three Rivers system (the catchment areas of the Kiso River, Nagara River, and Ibi River are called "the Kiso Three River system") included Gifu City, Gifu Prefecture of Japan, was frequently damaged by inundation after heavy rainfall. Our research aims to evaluate flood risk changes by river improvement in the Kiso Three River system fin the past hundred years. For that reason, we simulated in several times on flood inundation in the large, medium and low scale case in the urban area of Gifu city with 2D flood inundation model, and compared the distribution of flood depth. The results, the flood inundation area in urban area for small scale flood disaster dramatically is reduced from $3.82 \mathrm{~km}^{2}$ in the past time to $0.48 \mathrm{~km}^{2}$ in the current time with the progress of river infrastructure improvement. However flooded area in urban area for large and middle scale disaster show the almost same. It is suggested that flood risks in urban area are dramatically improved for only small disaster.
\end{abstract}

\section{INTRODUCTION}

Gifu Prefecture was a frequent flood occurred area where damaged by the Kiso Three Rivers system since a long time ago. For this reason, river improvements and infrastructures are constructed on the branches of the Kiso Three river system from the 1900 s to the current, which after construction the damage of the flood dramatically decreased. Although the risk of floods has reduced due to river improvements, it is finding that there are significant fluctuations in population and land use from 1920 to 2015. Such the phenomenon that the development of floodplain advances by embankment and development of levee is called "Levee Effect", and several studies have been conducted (Collenteur et al., 2015; Baldassarre et al., 2013). However, in these studies only studies using basic social data such as qualitative analysis and short-term population change are being conducted. On the other hand, Ito and Nakamura (2018), constructed long-term land use data and levee length database and found that urbanization progressed in the specific area after the levee was established.

However, it is not enough to evaluate how flood risks have been changing by the river infrastructure improvement, the rapid urbanization and land use changes, using 2D flood inundation simulation. In this research, the authours investigate flood risk changes in the past 100 years with $2 \mathrm{D}$ flood inundation simulation analysis considered with 100 years ago and current topographical and river infrastructure situations. Also, land use changes have been evaluated and compared with simulated flood risks in order to investigate the relationship the levee development and urbanization and flood risk changes.

\section{STUDY AREA AND DATA}

\subsection{The study area}

Figure 1 shows the location of the study area in Gifu city, Gifu Prefecture, Japan. The study area is the locating on the right levee side of the Nagara River, around Gifu city where the land use greatly changed that river width of each river is widening, and the route of each river is changing in the past hundred years. Here, we used the $1 / 20,000$ scale topographical maps from 1891 to 1893 (Meiji 24 to 26 in Japanese calendar) surveyed by The Ministry of the Imperial Japanese Land survey to produce the past topographical map in Meiji era (mainly in 1891), and also used the 1/25,000 topological maps from 2002 to 2009 (Heisei 21 to 26 in Japanese calendar) corresponded by the Geospatial Information Authority of Japan to produce the current topographical map in Heisei era (mainly in 2009). Figure 2 shows the past topographical map and figure 3 also shows the current topographical. Blue area is river area Figure 2 shows the past Nagara river was diverted to two branch such as the Furu river and the Furu-furu river. On the other hand, figure 3 shows the current Nagara river improved to a main stream and some river stream disappears due to river improvement.

\subsection{Terrain information}

Flood inundation analysis needs land surface topography. However, there is no data like the numerical elevation model in the 1900s. For this reason, we read terrain information from the topographic map and interpolate the elevation value to create a numerical elevation model from old maps. A numerical elevation model of the current time is created with the same way. Based on the topographical maps of Figures 2 and 3, the terrain information such as contour line, reference points for ground surveying, height points and levee shape were digitized to shape file using ArcGIS software. The details of digitized terrain information are shown in Table 1. Here, height point shows the height from the average elevation around the point and often indicates the height of levee top from ground height. Contour lines are digitized under $40 \mathrm{~m}$ asl., because whole area of Gifu city is less than $20 \mathrm{~m}$ asl. Flood inundation analysis does not need high mountain topography. 


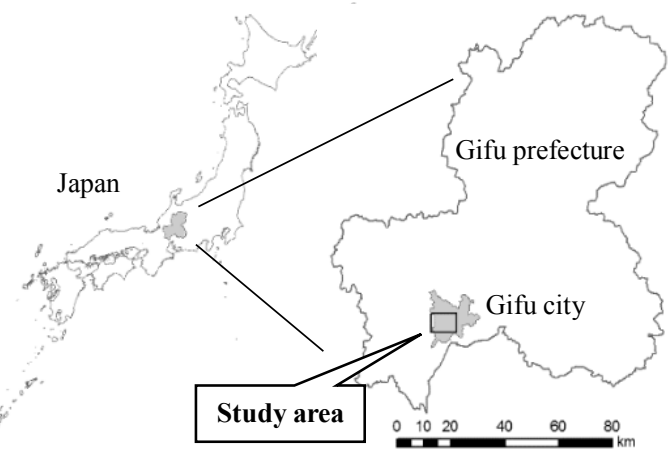

Figure 1. Location of the study area in Japan.

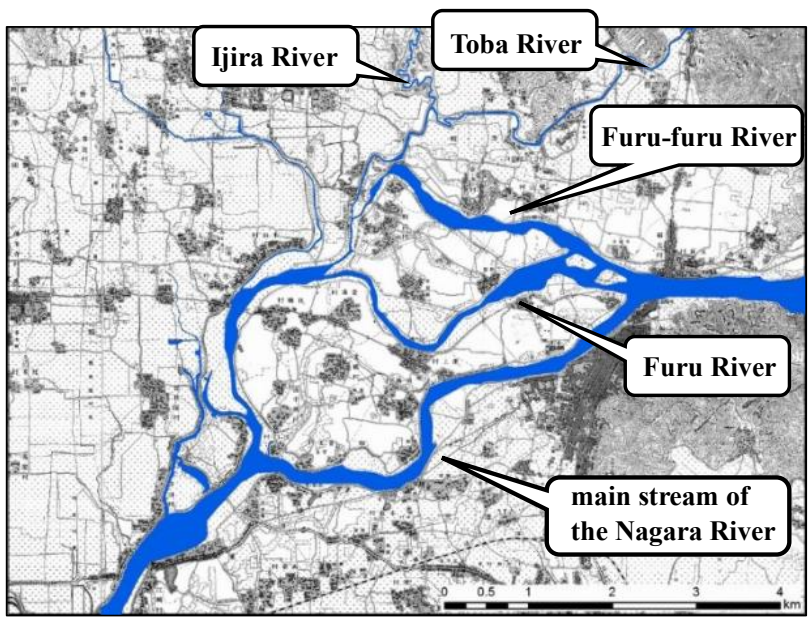

Figure 2. Topographical data in 1891(Meiji era).

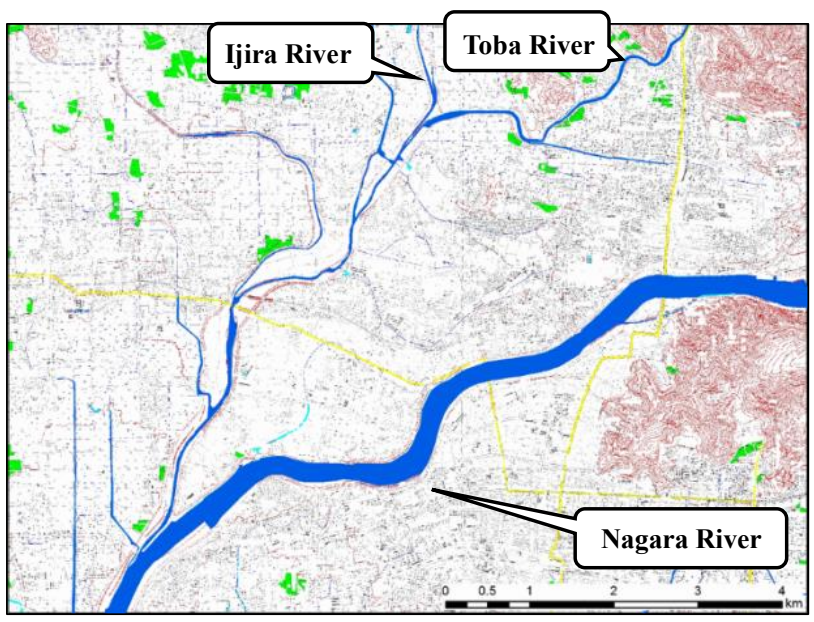

Figure 3. Topographical data in 2009 (Heisei era).

It is difficult to create a numerical elevation model, because contour lines, and reference points are not written in the river in the old topographic map. So, the contour lines which are interrupted in the river were joined in order to compensated for the elevation value in the river. Moreover, surrounding rivers other than the Nagara river and the Ijira river were also digitized, but small rivers that do not affect the flooding calculation were omitted. Figure 4 and 5 shows the digitized symbols for the past and current topographical maps. The digitized shape files are rasterized and interpolated to $10-\mathrm{m}$ grid by the method of Ohno and Tamura (2002) in order to flood inundation analysis.

\begin{tabular}{|c|c|c|c|}
\hline $\begin{array}{l}\text { Terrain } \\
\text { symbol }\end{array}$ & $\begin{array}{l}\text { Symbol sample } \\
\text { on map }\end{array}$ & $\begin{array}{l}\text { Layer } \\
\text { symbol }\end{array}$ & $\begin{array}{l}\text { Layer } \\
\text { type }\end{array}$ \\
\hline Contour & & & polyline \\
\hline Levee & & & polyline \\
\hline River & & & polygon \\
\hline $\begin{array}{l}\text { Reference } \\
\text { point }\end{array}$ & & & point \\
\hline Height points & Lig ing $^{\prime \prime}$ & & point \\
\hline
\end{tabular}

Table 1. Digitized Symbols.

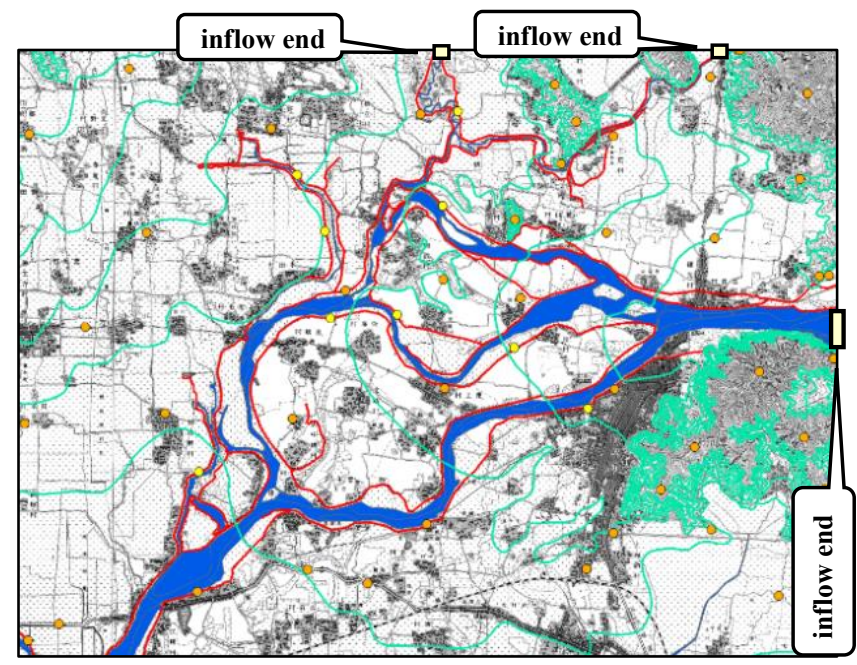

Figure 4. Digitized symbols in 1891 (Meiji era).

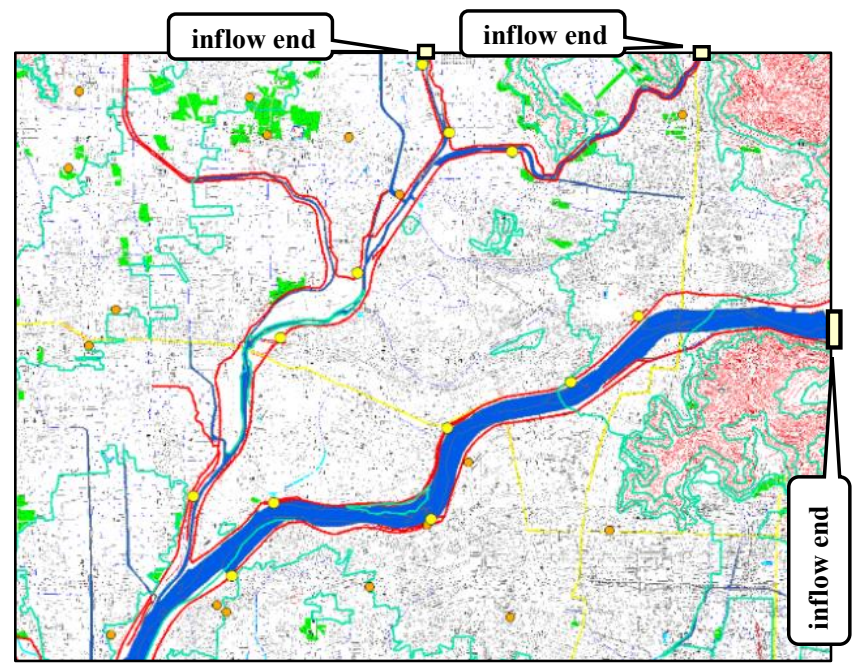

Figure 5. Digitized symbols in 2009 (Heisei era). 


\subsection{Land use data}

Land use/cover in the study area are dramatically changed from 1891 to 2009. Figures 6 and 7 are shown the land use changes from 1891 to 2009 . These land use data are digitized from the topographical maps in Meiji era and Heisei era (Ito and Nakamura, 2018). The land use is categorized into 8 classes such as urban area, public area, factory, forest, farmland, paddy field, wasteland and water area. In Meiji era, urban area extended to the left levee of the main stream of the Nagara River. The almost area between the Nagara River and Ijira River is covered by farmland. On the other hand, urban area extends to both sides of the main stream of the Nagara River in Heisei era. Figure 6 and 7 show that the urban area have dramatically developed in the last 100 years in the study area.

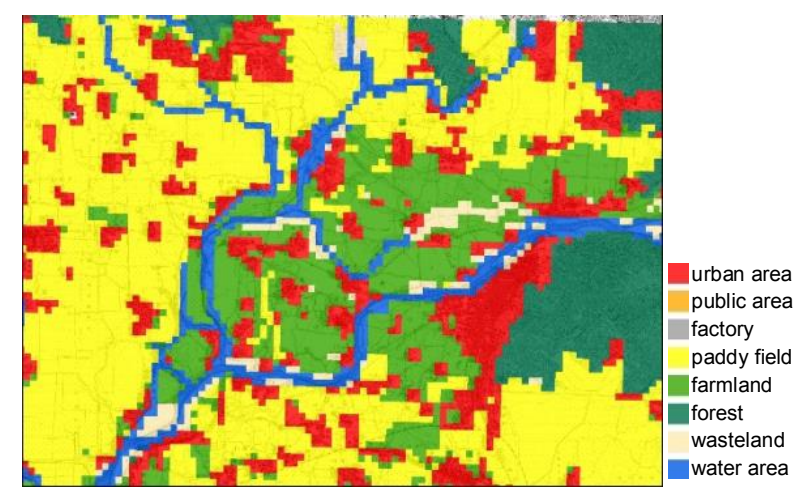

Figure 6. Land use map in 1891(Meiji era).

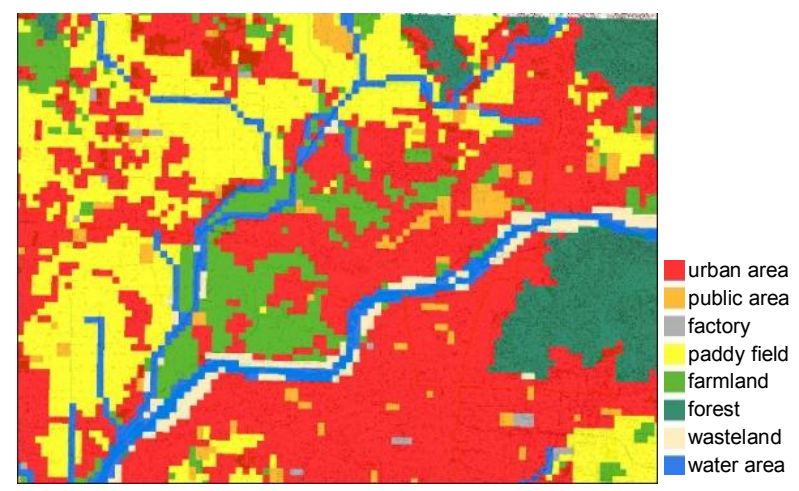

Figure 7. Land use map in 2009 (Heisei era).

\section{METHOD}

\subsection{Flood simulation model}

In this study, iRIC Nays 2D Flood (Shimizu, 2014), an analytical solver for calculation of unsteady two-dimensional plane flow and riverbed deformation using boundary-fitted coordinates within general curvilinear coordinates is used to flood inundation simulation. iRIC Nays 2D Flood requires topographic data and calculation conditions to perform flooding calculation. The general operation for iRIC simulations is performed on the Windows system, with the following continuity and momentum equations of two-dimensional unsteady flow in the Cartesian coordinate system:
Continuity equation:

$$
\frac{\partial h}{\partial t}+\frac{\partial(h u)}{\partial x}+\frac{\partial(h v)}{\partial y}=r
$$

Momentum equations:

$$
\begin{gathered}
\frac{\partial(u h)}{\partial t}+\frac{\partial\left(h u^{2}\right)}{\partial x}+\frac{\partial(h u v)}{\partial y}=-h g \frac{\partial H}{\partial x}-\frac{\tau_{x}}{\rho}+D^{x} \\
\frac{\partial(v h)}{\partial t}+\frac{\partial(h u v)}{\partial x}+\frac{\partial\left(h v^{2}\right)}{\partial y}=-h g \frac{\partial H}{\partial y}-\frac{\tau_{y}}{\rho}+D^{y} \\
\frac{\tau_{x}}{\rho}=C_{f} u \sqrt{u^{2}+v^{2}} \\
\frac{\tau_{y}}{\rho}=C_{f} v \sqrt{u^{2}+v^{2}} \\
D^{x}=\frac{\partial}{\partial x}\left[v_{t} \frac{\partial(u h)}{\partial x}\right]+\frac{\partial}{\partial y}\left[v_{t} \frac{\partial(u h)}{\partial y}\right] \\
D^{y}=\frac{\partial}{\partial x}\left[v_{t} \frac{\partial(v h)}{\partial x}\right]+\frac{\partial}{\partial y}\left[v_{t} \frac{\partial(v h)}{\partial y}\right] \\
C_{f}=\frac{g^{\prime}}{h^{1 / 3}} u_{*} h
\end{gathered}
$$

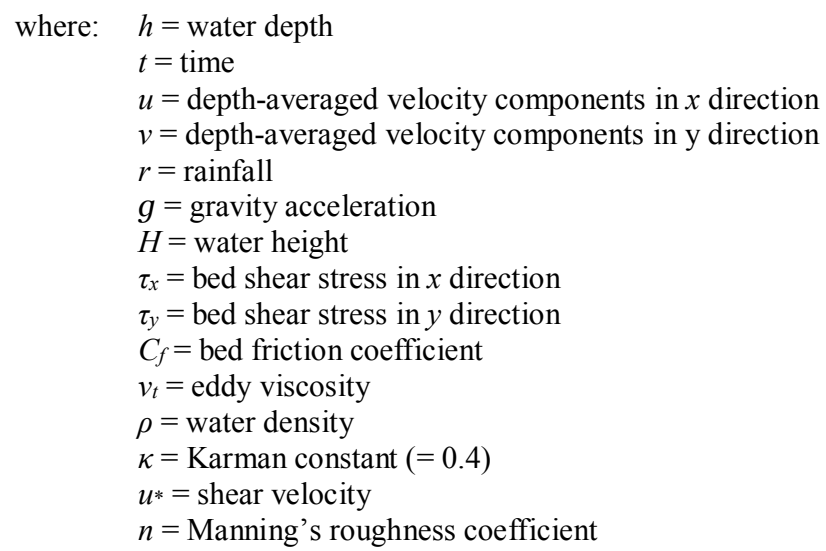

\subsection{Computational conditions}

When performing flooding calculation using iRIC Nays 2D Flood, in addition to the numerical elevation model created in the previous chapter, the setting of a hydrograph showing the inflow and flow rate from each river, boundary condition of calculation lattice and a time step of the calculation are necessary to set. The flood calculation was carried out with three hydrographs set in Section 3.2.1 for the two numerical elevation models of Gifu city in the past and the current time.

3.2.1 Hydrograph: In this study, inflow hydrographs are set to the three river such as the Nagara River, Ijira River and Toba River. The Nagara River basin is about $1620 \mathrm{~km}^{2}$. On the other hand, the Ijira River and Toba River are relatively small basin as 
about $48 \mathrm{~km}^{2}$ and $55 \mathrm{~km}^{2}$. The inflow hydrograph of the Nagara River is defined with the basic high water which is used for the basic policy of river improvement announced on August 31, 2007, by the Ministry of Land, Infrastructure and Transportation (2007), and determined as figure 8 . The peak flow rate of the reference hydrograph of the Nagara River is $8900 \mathrm{~m}^{3} / \mathrm{s}$. And its time series are referenced the heavy rainfall event in November, 2000. There is no reference hydrograph for the Ijira and Toba River. Thus, the Ijira River hydrograph was prepared by the following procedure.

1) The peak flow rate $Q_{p}\left(\mathrm{~m}^{3} / \mathrm{s}\right)$ is set using the rational formula as eq. (10).

$$
Q_{p}=f_{p} \frac{1}{3.6} r A
$$

where:

$$
\begin{aligned}
& f_{p}=\text { peak runoff coefficient } \\
& r=\text { average rainfall intensity }(\mathrm{mm} / \mathrm{h}) \\
& A=\text { catchment area }\left(\mathrm{km}^{2}\right)
\end{aligned}
$$

2) Set the time to reach the peak flow rate from the flood arrival time formula as eq. (11). The current data is used for the flow path length and average slope of the river.

$$
T_{p}=1.67 \times 10^{-3}(L / \sqrt{S})^{0.7}
$$

where: $\quad T_{p}=$ flood arrival time (s)

$L=$ flow path length of the river $(\mathrm{km})$

$S=$ mean slope

3) Make a hydrograph using the kinematic wave method's motion equation as eq. (12) and the decreasing curve equation as eq.(13). Use eq. (12) when the flow rate increases and eq. (13) when the flow rate decreases.

$$
\begin{aligned}
& Q_{t}=\frac{\sqrt{\sin \theta}}{N}(r t)^{\frac{5}{3}} B \\
& Q_{t}=Q_{0} K^{-\left(t-t_{0}\right)}
\end{aligned}
$$

where: $\quad Q_{t}=$ flow rate at time $\mathrm{t}\left(\mathrm{m}^{3} / \mathrm{s}\right)$

$B=$ river width $(\mathrm{m})$

$\theta=$ river bed slope

$N=$ equivalent roughness of river bed

$Q_{0}=$ flow rate at the time $t_{0}$

$K=$ constant

The base flow rate was defined as 5 hours from the start of inflow. Also, the base flow rate was $100 \mathrm{~m}^{3} / \mathrm{s}$ of the Nagara River and 20 $\mathrm{m}^{3} / \mathrm{s}$ of other small rivers. The inflow hydrographs created by the above method are shown in Figure 6. The peak flow rate of the Ijira and Toba Rivers are less than $100 \mathrm{~m}^{3} / \mathrm{s}$, so, the second panel of figure 6 shows the detail of the hydrographs of the Ijira and Toba rivers.

As mentioned above, the basic inflow hydrographs are defined as figure 8 . In this study, we prepared three patterns of hydrograph with peak flow as 1/4, 1/6 and 1/10 of the basic hydrographs shown in figure 8 , due to evaluate several disaster scale. The new patterns of hydrograph are shown in figure 9 . The peak flow rate of the basic (reference) hydrographs assume the disaster scale with 100 -y return period. The hydrographs with $1 / 4,1 / 6$ peak flow are assumed the middle scale disaster and 1/10 peak flow are assumed the small scale disaster.

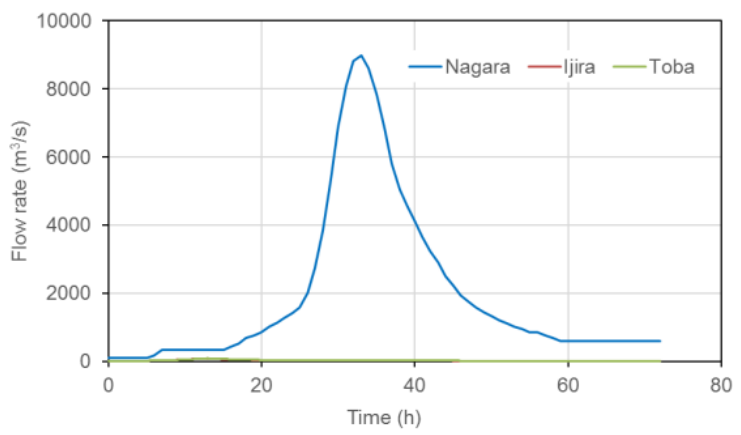

(a) Basic hydrographs of three rivers

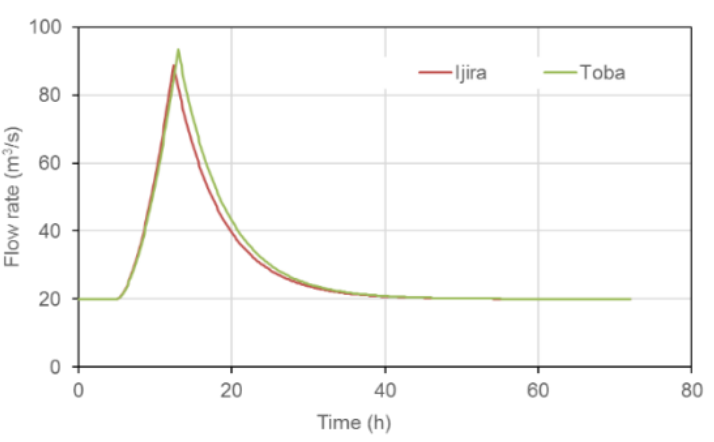

(b) Basic hydrographs of the Ijira and Toba Rivers

Figure 8. Basic inflow hydrographs for iRIC Simulation.

3.2.2 Parameter settings: When performing flood inundation simulation, it is necessary to set boundary conditions, calculation grid, calculation time step, etc. The set parameters are summarized in Table 2. The inflow end of each river is set the upstream end of each river on the study area boundary line. The inflow ends are shown as black rectangle boxes in figure 4 and 5 . Mentioned hydrographs are input from these inflow end into flood simulation boundary area. The boundary conditions are free-flowing at the southern and the western end of the grid, and the other flows are inflows. The following conditions must be taken into consideration in the size and time step of the

\begin{tabular}{|c|c|c|}
\hline \multirow{2}{*}{$\begin{array}{l}\text { Number of } \\
\text { grids }\end{array}$} & $x$ direction & 950 \\
\hline & $y$ direction & 700 \\
\hline \multirow{2}{*}{ Grid size (m) } & $x$ direction & 10 \\
\hline & $y$ direction & 10 \\
\hline \multicolumn{2}{|c|}{ Method of difference method } & Upwind difference \\
\hline \multicolumn{2}{|c|}{ Calculation time step (s) } & 0.5 \\
\hline \multirow{4}{*}{$\begin{array}{l}\text { Boundary } \\
\text { condition }\end{array}$} & East end & inflow \\
\hline & West end & outflow \\
\hline & North end & inflow \\
\hline & South end & outflow \\
\hline \multirow{2}{*}{$\begin{array}{l}\text { Roughness } \\
\text { coefficient }\end{array}$} & Rivers & 0.01 \\
\hline & Other than river & 0.06 \\
\hline \multirow{2}{*}{$\begin{array}{l}\text { Land using } \\
\text { type }\end{array}$} & Residential & 0.5 \\
\hline & Non-residential & 0 \\
\hline
\end{tabular}
calculation grid.

$$
\Delta x>u \Delta t
$$

where: $\quad u=$ flow rate in the $x \operatorname{direction}(\mathrm{m} / \mathrm{s})$

$\Delta x=$ calculation grid size in the $x$ direction $(\mathrm{m})$

$\Delta t=$ calculation time step $(\mathrm{s})$

Table 2. Parameters 


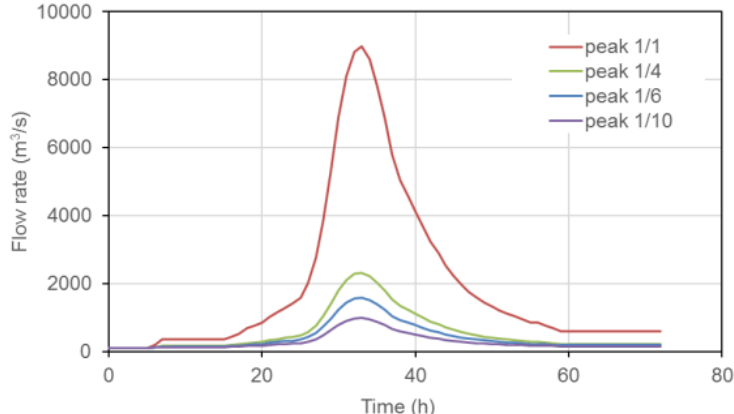

(a) the Nagara River

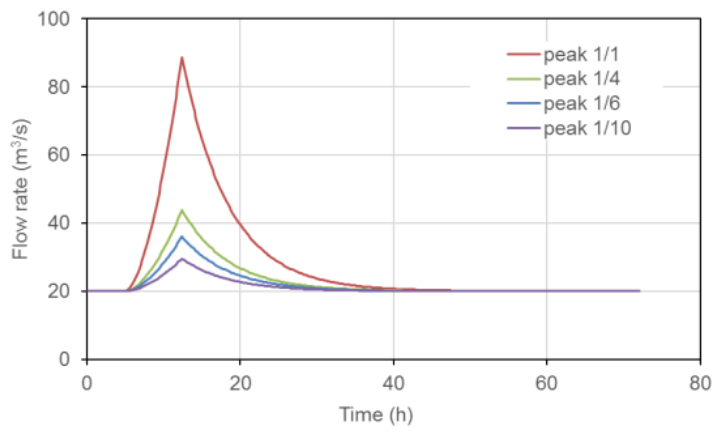

(b) the Ijira River

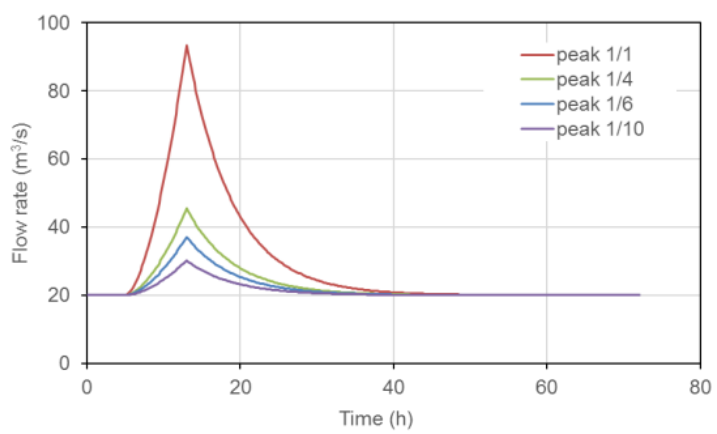

(c) the Toba River

Figure 9. Modified hydrographs for iRIC Simulation.

The grid size was $10 \mathrm{~m} \times 10 \mathrm{~m}$, and the calculation time step was $0.5 \mathrm{~s}$. If the calculation time step is too small, the time required for the calculation becomes very long. To do all the flooding calculations, we set the calculation time step to this value.

\section{RESULTS AND DISCUSSION}

\subsection{Flood simulation results}

Flood simulation performed with the modified hydrographs for each era. The simulated flood inundation area using the basic hydrographs with $1 / 1$ peak flow rate covered over the almost all of the study area. Because the differences of simulated flood inundation area between two eras were not so obvious, we used the modified hydrographs to compare the disaster risks of two eras. Figure 10 shows the distribution of the maximum flood inundation depth simulated with the modified hydrographs with $1 / 4,1 / 6$ and $1 / 10$ peak in 1890 (Meiji era). The simulation results with $1 / 4$ and $1 / 6$ peak have the almost same flood inundation area Only the urban area on the left levee side of the Nagara River were not flooded. The area near by the Mount Kinka is relatively higher elevation area. The almost all area between the branches of the Nagara River as the Furu and Furu-furu River were flooded. The simulation results with $1 / 10$ peak showed relatively less flood inundation area than the other results. The many area on the left levee side of the Nagara River were not flooded. This area becomes to urban area in 2009.

Figure 11 shows the distribution of the maximum flood inundation depth simulated with the modified hydrographs with $1 / 4,1 / 6$ and $1 / 10$ peak in 2009 (Heise era). Figure 11 shows the flood inundation area are reduced from Meiji era. Figure 12

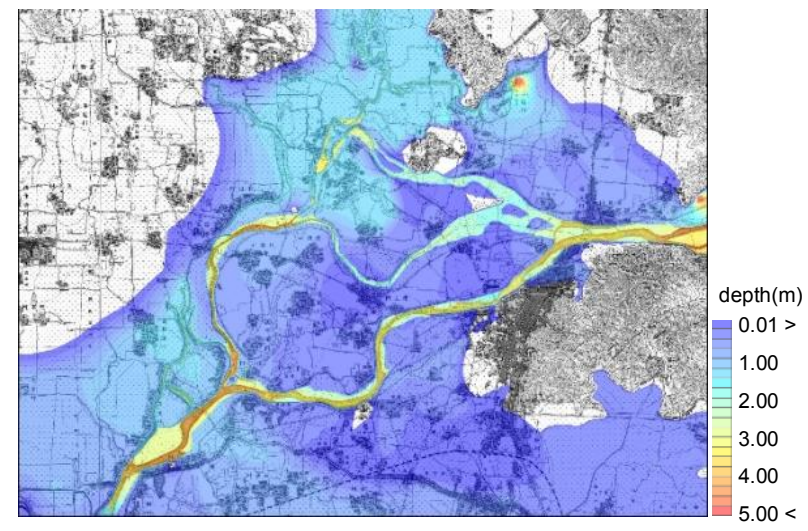

(a) Maximum flood depth with $1 / 4$ hydrograph

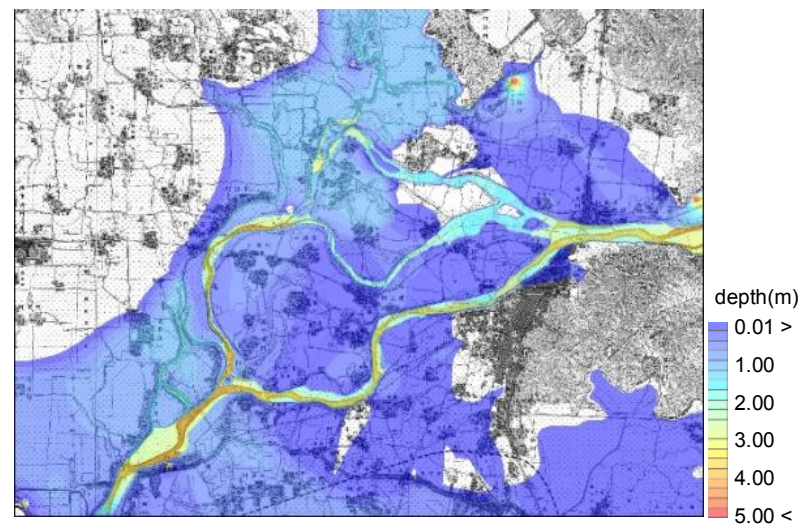

(b) Maximum flood depth with 1/6 hydrograph

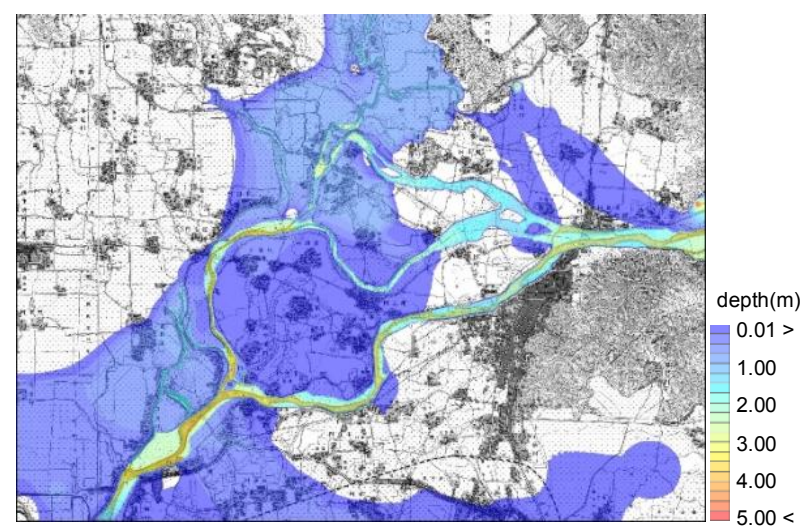

(c) Maximum flood depth as 1/10 hydrograph

Figure 10. Distribution of maximum flood depth in 1891. 


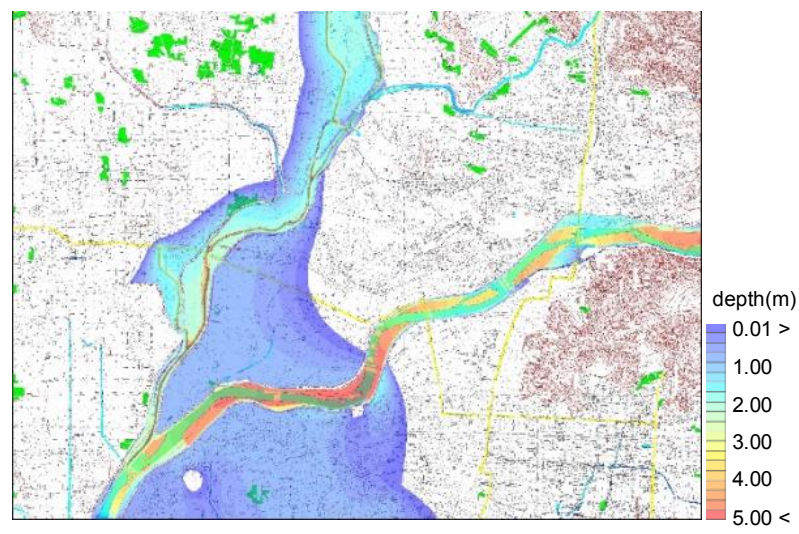

(a) Maximum flood depth with $1 / 4$ hydrograph

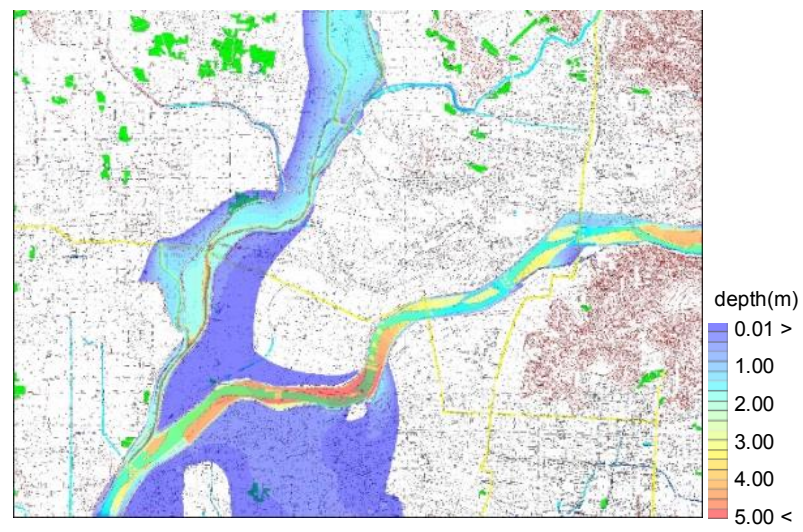

(b) Maximum flood depth with 1/6 hydrograph

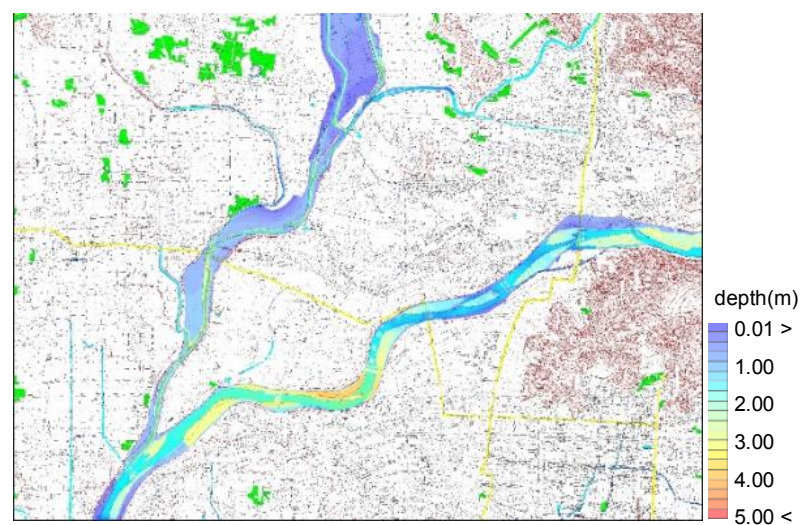

(c) Maximum flood depth as $1 / 10$ hydrograph

Figure 11. Distribution of maximum flood depth in 2009.

shows the comparison of the flood inundation area with each flood disaster scale as peak modification value. The flood inundation area with $1 / 4$ peak in 2009 are less than $1 / 10$ peak in 1891. The flood inundation area is greatly reduced. It is indicated that the river improvement has worked effectively for medium or less scale flood disaster.

\subsection{Overlay with land use map}

It is confirmed that the total flood inundation area is reduced by river improvement from 1891 to 2009. On the other hand, because urban area is expanding in the last 100 years, as we mentioned in figures 6 and 7, the assessment of flood risk in urban area is also important. Therefore, we calcurate the flood inundation area in urban area as figure 13 with overlaying the flood inundation cover map and land use map. Figure 13 shows flood inundation area in urban area for 1891 and 2009 are the almost same with $1 / 4$ and 1/6 peak hydrographs. However, the results with $1 / 10$ peak hydrograph are dramatically reduced from $3.82 \mathrm{~km}^{2}$ in 1891 to $0.48 \mathrm{~km}^{2}$ in 2009 . For middle scale flood disaster as $1 / 4$ and $1 / 6$ peak, it is suggested that flood risks in urban area are not decreased, because decreasment of flood risk by river improvement competed with urbanization around river stream. However, for small scale flood disaster as $1 / 10$ peak, the flood risk is dramatically reduced. It is suggested that the urban are hardly never flooded for small scale disaster. We also compared the maximum flood depths in urban area as figure 14 . Maximum flood depths are slightly decreased from Meiji era to Heisei era. And the difference of flood depth for small scale disaster is only a little, different from the results of flood inundation area.

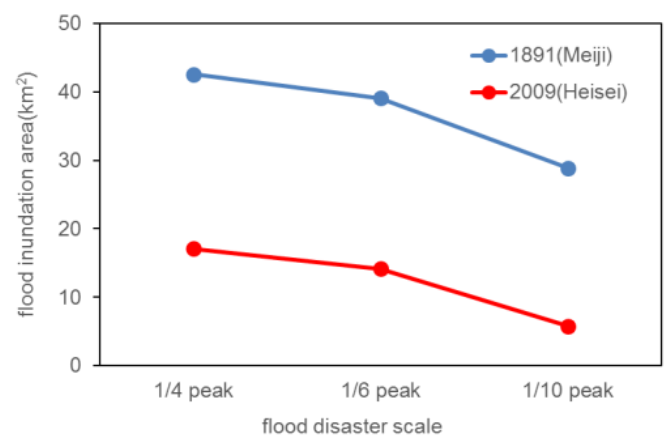

Figure 12. Comparison of flood inundation area for whole of the study area.

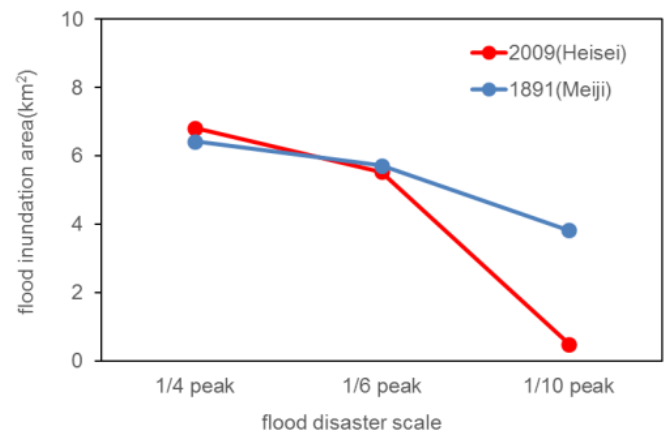

Figure 13. Comparison of flood inundation area for urban area.

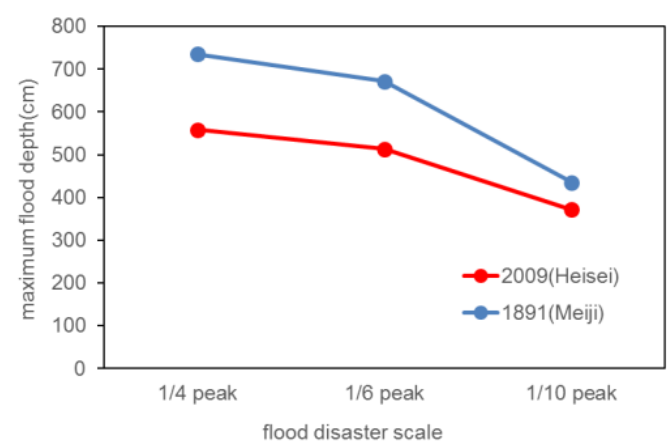

Figure 14. Comparison of maximum flood depths for urban area. 


\section{CONCLUSION}

In this study, the authors investigate the relationship flood risk changes and land use changes with 2D flood inundation simulation in order to evaluate "Levee Effect" in Gifu City, Japan. The river infrastructure and stream networks of the Nagara River in Gifu City, Japan were improved in this past 100 years. The topographical maps in 1891 and 2009 are digitized in order to provide terrain data for flood inundation simulation. From the results of flood inundation simulation, it is shown that the flood inundation area for the same disaster scale have been decreased with the progress of river infrastructure improvement. However, only in urban area, the flood inundation area for large and middle scale flood disaster are the almost same, the flood risks are not so much improved with the progress of river infrastructure improvement. On the other hands, flooded area in urban area for small scale flood disaster dramatically is reduced from $3.82 \mathrm{~km}^{2}$ in the past time to $0.48 \mathrm{~km}^{2}$ in the current time. The above results suggest that decreasment of flood risk by river improvement for large and middle disaster competed with urbanization around river stream. Recent flood risk reduction by river infrastructure improvement in urban area especially affects to small scale disaster, and only small influence to large and middle scale disasters. These results provide the important knowledge for investigation of "Levee Effect".

\section{ACKNOWLEDGEMENT}

The atuhors would like to thank Prof. Shinichiro Nakamura, who provide the land use data used in this research.

\section{REFERENCES}

Baldassarre, G. D., Viglione, A., Carr, G., Kuil, L., Salinas, J. L. and Bloschl, G., 2013. Socio-hydrology: conceptualizing humanflood interactions, Hydrology and Earth System Sciences, 17, 3295-3303.

Collenteur, R. A., Model, H., Jongman, B. and Baldassarre, G. D., 2015. The failed-levee effect; Do societies learn from flood disasters?, Nat Hazards, 76, 373-388.

Ito, Y. and Nakamura, S., 2018. Development of long-term land use data in the Kiso River basin and quantitative evaluation of Levee Effect, Proceedings of Japan Society of Hydrology and Water Resouces, 31, 298-299 (in Japanese).

Shimizu, Y., Inoue, T., Suzuki, E., Iwasaki, T., Hamaki, M. and Yoshida, T., 2014. "iRIC Software Nays 2D Flood Solver Manual"

Ohno, H., and Tamura, E., 2002. The method to calculate DEM data with $1 / 25,000$ scale vector geographic information, Journal of the Geographical Survey Institute Authority of Japan, 99, 33-38 (in Japanese).

Ministry of Land, Infrastructure and Transport, 2007. The Kiso River water system river improvement basic policy -document about basic high water-, www.mlit.go.jp/river/shinngikai_blog/shaseishin/kasenbunkakai /shouiinkai/kihonhoushin/070831/pdf/ref8-1.pdf (19 July, 2019) (in Japanese). 